\title{
Development and Validation of Prognostic Nomograms for Patients with Colon Neuroendocrine NeoplasmsPrognostic Nomograms for Colon Nens' Patients
}

\section{Ruitong Xu}

Jiangsu Province Hospital and Nanjing Medical University First Affiliated Hospital

\section{Bingrong Zhou}

Jiangsu Province Hospital and Nanjing Medical University First Affiliated Hospital

\section{Ping Hu}

Jiangsu Province Hospital and Nanjing Medical University First Affiliated Hospital

\section{Bingyan Xue}

Jiangsu Province Hospital and Nanjing Medical University First Affiliated Hospital

\section{Danyang Gu}

Jiangsu Province Hospital and Nanjing Medical University First Affiliated Hospital

\section{Xiaolin Li}

Jiangsu Province Hospital and Nanjing Medical University First Affiliated Hospital

Qiyun Tang ( $\sim$ tqy831@163.com )

Jiangsu Province Hospital and Nanjing Medical University First Affiliated Hospital

\section{Research Article}

Keywords: colon neuroendocrine neoplasm, nomogram, prognosis, survival

Posted Date: May 12th, 2021

DOl: https://doi.org/10.21203/rs.3.rs-498244/v1

License: (c) (1) This work is licensed under a Creative Commons Attribution 4.0 International License. Read Full License

Version of Record: A version of this preprint was published at World Journal of Surgical Oncology on August 7th, 2021. See the published version at https://doi.org/10.1186/s12957-021-02338-8. 


\section{Abstract \\ Background}

Colon neuroendocrine neoplasms (NENs) have one of the poorest median overall survival (OS) rates among all NENs. The American Joint Committee on Cancer (AJCC) tumor-node-metastasis (TNM) staging system-currently the most commonly used prediction model-has limited prediction accuracy because it does not include parameters such as age, sex, and treatment. The aim of this study was to construct nomograms containing various clinically important parameters to predict the prognosis of patients with colon NENs more accurately.

\section{Methods}

Using the Surveillance, Epidemiology and End Results (SEER) database, we performed a retrospective analysis of colon NENs diagnosed from 1975 to 2016. Data were collected from 1196 patients, most of which were female $(617 / 1196,51.6 \%)$, and the average age was $61.94 \pm 13.05$ years old. Based on the optimal cutoff value in age (age 0-55 y, 55-67 y, age $\geq 68 \mathrm{y}$ ), 396 (33.1\%) patients were between 0-55y, $408(34.1 \%)$ were between $56-67 \mathrm{y}$ and $392(32.8 \%)$ were $\geq 68$ y. Patients were randomized into training and validation cohorts (3:1). Independent prognostic factors were used for construction of nomograms to precisely predict OS and cancer-specific survival (CSS) in patients with colon NENs.

\section{Results}

Multivariate analysis showed that age $\geq 68$ years, sex, tumor size, grade, chemotherapy, $\mathrm{N}$ stage, and $\mathrm{M}$ stage were independent predictors of OS. In the validation cohort, the Concordance index (C-index) values of the OS and CSS nomograms were 0.8345 (95\% confidence interval [Cl], 0.8044-0.8646) and 0.8209 (95\% Cl, 0.7808-0.861), respectively. C-index also indicated superior performance of both nomograms (Cindex 0.8347 for OS and 0.8668 for CSS) compared with the AJCC TNM classification (C-index 0.7159 for OS and 0.7366 for CSS).

\section{Conclusions}

We established and validated new nomograms for more precise prediction of OS and CSS in patients with colon NENs to facilitate individualized clinical decisions.

\section{Background}

Neuroendocrine neoplasms (NENs) are a heterogeneous group of rare tumors derived from peptidergic neurons and neuroendocrine cells of the diffuse neuroendocrine system. According to tumor differentiation, NENs include well- or moderately differentiated neuroendocrine tumor (NET), poorly 
differentiated neuroendocrine carcinoma (NEC), and mixed neuroendocrine non-neuroendocrine neoplasm (MiNEN). Biological behavior of NET is relatively benign compared with NEC or mixed adenoneuroendocrine carcinoma (MANEC)[1]. A population-based study from nationally representative data from the Surveillance, Epidemiology, and End Results (SEER) program showed that the incidence of NENs has increased from $1.09 / 100,000$ in 1973 to $6.98 / 100,000$ in 2012 [2]. The gastroenteropancreatic tract is the most common site of extrapulmonary NENs. Among them, NENs originating from the cecum to the sigmoid colon account for 4-8\% of all NENs [2-6]. Although colon and rectal NENs are often described as a single disease, recent evidence has indicated that colon NENs have one of the poorest median overall survival (OS) rates among NENs and a much worse prognosis than rectal NENs [2]. Clinically, colon NENs are highly aggressive, poorly differentiated, and have very limited treatment options, which leads to worse outcomes $[1,7,8]$.

The American Joint Committee on Cancer (AJCC) and the World Health Organization (WHO) have proposed systems to predict the prognosis of colon NENs [9-10]. The AJCC tumor-node-metastasis (TNM) staging system includes T stage, $\mathrm{N}$ stage, and $\mathrm{M}$ stage, whereas the WHO classification includes the mitotic count and Ki-67 proliferation index. Currently, these systems are the most commonly used prediction models for colon NENs, but they contain only 2-3 parameters and do not incorporate certain parameters, such as age, sex, and treatment [11], which are equally important for the prognosis of patients with colon NENs. Therefore, there is an urgent need for a usable decision tool that can integrate additional parameters to assist with clinical practice, decision-making, and accurate prediction in patients with colon NENs.

Nomograms-graphical calculations or algorithms with continuous scales to calculate the probability of a particular outcome-have recently been shown to be a more effective method for predicting the prognosis of various cancers than traditional staging systems [12-15]. However, no studies have established a prognostic nomogram to predict the outcomes of patients with colon NENs.

To the best of our knowledge, this study is the first attempt to develop nomograms of colon NENs based on a retrospective study of the SEER database that incorporates additional clinical parameters to predict survival more accurately.

\section{Materials And Methods}

\subsection{Data retrieved from SEER}

Specific clinicopathological data and prognostic outcomes of patients with colon NENs were retrieved from the SEER database submitted on November 2018 [16]. This study did not require a local ethics approval or statement because all the data were publicly available. The International Classification of Diseases for Oncology (ICD-0-3) was used to identify cases of colon NENs. The primary site code (C18.0, C-18.2-C18.9, colon) and the following ICD-0-3 codes for histological type were used to identify cases with colon NENs: Large cell neuroendocrine carcinoma (8013), Small cell carcinoma (8041), Carcinoid 
tumor (8240), Enterochromaffin cell carcinoid (8241), Neuroendocrine carcinoma (8244), Mixed adenoneuroendocrine carcinoma (MANEC) (8246), and Atypical carcinoid tumor (8249). The inclusion criteria were as follows: (I) complete TNM stage information available; (II) only one primary tumor lesion; (III) all data classified using the new 8th Edition the AJCC staging system; (IV) complete survival data available; (V) no missing data in the SEER other cause of death classification; (VI) known tumor size; and (VII) known grade. Patients conforming to the following conditions were excluded: (I) patients with other tumors at the same time; (II) unknown stage information; and (III) patients without complete clinical data (e.g., tumor size, treatment, grade). These selection criteria resulted in 1196 eligible patients with colon NENs enrolled, who were subsequently randomly assigned into a training cohort and a validation cohort. In addition, patients were grouped based on age into three categories ( $0-55$ years, $56-67$ years, and $\geq 68$ years); they were also grouped based on the size of the tumor into $<35 \mathrm{~mm}$ and $\geq 35 \mathrm{~mm}$ groups.

\subsection{Study variables}

We retrieved the following demographic or clinical variables from the SEER database: age, sex, tumor grade, tumor site, tumor size, AJCC TNM stage, surgery and chemotherapy, SEER other cause of death classification, and survival-related information. The stage classification according to the criterion of the 8th AJCC TNM staging system. The primary endpoint was OS, whereas the secondary endpoint was cancer-specific survival (CSS).

\subsection{Construction and validation of nomogram model}

The entire sample was randomized into two groups; 896 (approximately 75\%) cases were included in the training cohort and 300 (approximately $25 \%$ ) in the validation cohort. At diagnosis, patient age (years) and survival time (months) were expressed as mean \pm SD or median (25th-75th percentile) with appropriate distribution. The Mann-Whitney Utest was used for analysis of continuous variables, and chi-square test was used for comparison of categorical variables between groups of patients who survived or not. Univariate and multivariate Cox proportional-risk regressions were used to assess factors associated with patient's OS and CSS. By using univariate Cox analysis to determine the potential prognostic factors associated with OS and CSS of colon NENs, variables with $P<0.05$ were included in the final multivariate analysis and construction of the nomogram. The receiver operating characteristic (ROC) curves were analyzed by measuring the performance of the constructed nomogram. The accuracy of the nomogram was analyzed using the Harrell C-index and the area under the time-dependent ROC curve (AUC). A larger C-index is associated with better predictive ability of the nomogram [20]. Calibration curves were plotted to assess the agreement between the nomogram-predicted survival rate and the observed survival rate. Furthermore, $\mathrm{C}$-index of the nomogram was compared with C-index of the TNM stage. In summary, the nomograms were constructed to predict the survival of colon NENs patients. All analyses were performed with the statistical package R (http://www.r-project.org) and Empower Stats software (http://www.empowerstats.com, X\&Y Solutions, Inc., Boston, MA). Statistical significance was set at $P<0.05$.

\section{Results}




\subsection{Baseline characteristics of patients}

A total of 1196 patients with colon NENs from the SEER databases were included in this study, with 896 patients in the training cohort and 300 patients in the validation cohort. The proportions of female and male patients were $51.6 \%$ and $48.4 \%$, respectively. Grade $\mathrm{G} 1, \mathrm{G} 2, \mathrm{G} 3$, and G4 accounted for $39.8 \%, 16 \%$, $29.1 \%$, and $15.1 \%$ of cases, respectively. The primary site was in the right hemicolon in $76.5 \%$ of cases, while $23.5 \%$ were located in the left hemicolon. The median tumor size was $41.0 \mathrm{~mm}$. Other characteristics are presented in Table 1. Overall, patients in the training and validation cohorts were comparable in terms of demographic and clinicopathological features (Table 1). 
Table 1

Demographic and clinical characteristics of patients in the training and validation cohorts

\begin{tabular}{|c|c|c|c|c|c|}
\hline \multirow[t]{2}{*}{ Variable } & \multicolumn{2}{|c|}{$\begin{array}{l}\text { Training cohort }(\mathrm{n}= \\
\text { 896) }\end{array}$} & \multicolumn{2}{|c|}{$\begin{array}{l}\text { Validation cohort }(n= \\
300)\end{array}$} & \multirow[t]{2}{*}{$\begin{array}{l}P \\
\text { value }\end{array}$} \\
\hline & $\begin{array}{l}\text { No. of } \\
\text { patients }\end{array}$ & $\%$ & $\begin{array}{l}\text { No. of } \\
\text { patients }\end{array}$ & $\%$ & \\
\hline Median age, years & $61.8 \pm 13.0$ & & $62.3 \pm 13.1$ & & 0.599 \\
\hline Age, years & & & & & 0.666 \\
\hline $0-55$ & 303 & 33.8 & 93 & 31.0 & \\
\hline $56-67$ & 303 & 33.8 & 105 & 35.0 & \\
\hline$\geq 68$ & 290 & 32.4 & 102 & 34.0 & \\
\hline Sex & & & & & 0.919 \\
\hline Female & 463 & 51.7 & 154 & 51.3 & \\
\hline Male & 433 & 48.3 & 146 & 48.7 & \\
\hline Median tumor diameter, $\mathrm{mm}$ & $40.5 \pm 28.1$ & & $42.6 \pm 38.7$ & & 0.3 \\
\hline Tumor size, mm & & & & & 0.843 \\
\hline$<35$ & 433 & 48.3 & 143 & 47.7 & \\
\hline$\geq 7$ & 463 & 51.7 & 157 & 52.3 & \\
\hline Laterality & & & & & 0.812 \\
\hline Right & 687 & 76.7 & 228 & 76.0 & \\
\hline Left & 209 & 23.3 & 72 & 24.0 & \\
\hline Grade & & & & & 0.031 \\
\hline G1 & 357 & 39.8 & 119 & 39.7 & \\
\hline G2 & 139 & 15.5 & 53 & 17.7 & \\
\hline G3 & 277 & 30.9 & 71 & 23.7 & \\
\hline G4 & 123 & 13.7 & 57 & 19.0 & \\
\hline Pathology & & & & & 0.006 \\
\hline $\begin{array}{l}8013 / 3 \text { Large cell neuroendocrine } \\
\text { carcinoma }\end{array}$ & 67 & 7.5 & 23 & 7.7 & \\
\hline 8041/3 Small cell carcinoma & 37 & 4.1 & 10 & 3.3 & \\
\hline
\end{tabular}

Abbreviations: AJCC, American Joint Committee on Cancer; TNM, tumor-node-metastasis; OS, overall survival; CSS, cancer-specific survival. 


\begin{tabular}{|c|c|c|c|c|c|}
\hline \multirow{2}{*}{$\begin{array}{l}\text { Variable } \\
\text { 8240/3 Carcinoid tumor }\end{array}$} & \multicolumn{2}{|c|}{$\begin{array}{l}\text { Training cohort }(n= \\
\text { 896) }\end{array}$} & \multicolumn{2}{|c|}{$\begin{array}{l}\text { Validation cohort }(\mathrm{n}= \\
300)\end{array}$} & \multirow[t]{2}{*}{$\begin{array}{l}P \\
\text { value }\end{array}$} \\
\hline & 340 & 37.9 & 104 & 34.7 & \\
\hline $\begin{array}{l}8244 / 3 \text { Mixed adeno-neuroendocrine } \\
\text { carcinoma }\end{array}$ & 34 & 3.8 & 28 & 9.3 & \\
\hline 8246/3 Neuroendocrine carcinoma & 418 & 46.7 & 135 & 45.0 & \\
\hline Operation & & & & & 0.864 \\
\hline No operation & 33 & 3.7 & 10 & 3.3 & \\
\hline Local tumor excision & 76 & 8.5 & 23 & 7.7 & \\
\hline Curative & 787 & 87.8 & 267 & 89.0 & \\
\hline Chemotherapy & & & & & 0.82 \\
\hline No & 645 & 72.0 & 218 & 72.7 & \\
\hline Yes & 251 & 28.0 & 82 & 27.3 & \\
\hline AJCC TNM Stage(8th ) & & & & & 0.337 \\
\hline 1 & 109 & 12.2 & 31 & 10.3 & \\
\hline$\| \mathrm{A}$ & 23 & 2.6 & 5 & 1.7 & \\
\hline IIB & 58 & 6.5 & 28 & 9.3 & \\
\hline IIIA & 11 & 1.2 & 6 & 2.0 & \\
\hline IIIB & 376 & 42.0 & 132 & 44.0 & \\
\hline IV & 319 & 35.6 & 98 & 32.7 & \\
\hline AJCC T Stage(8th ) & & & & & 0.066 \\
\hline T1 & 5 & 0.6 & 2 & 0.7 & \\
\hline T1a & 96 & 10.7 & 28 & 9.3 & \\
\hline $\mathrm{T} 1 \mathrm{~b}$ & 33 & 3.7 & 7 & 2.3 & \\
\hline T2 & 104 & 11.6 & 24 & 8.0 & \\
\hline T3 & 447 & 49.9 & 144 & 48.0 & \\
\hline T4 & 211 & 23.5 & 95 & 31.7 & \\
\hline AJCC N Stage(8th ) & & & & & 0.968 \\
\hline
\end{tabular}

Abbreviations: AJCC, American Joint Committee on Cancer; TNM, tumor-node-metastasis; OS, overall survival; CSS, cancer-specific survival. 


\begin{tabular}{|c|c|c|c|c|c|}
\hline \multirow{2}{*}{$\begin{array}{l}\text { Variable } \\
\text { NO }\end{array}$} & \multicolumn{2}{|c|}{$\begin{array}{l}\text { Training cohort }(n= \\
\text { 896) }\end{array}$} & \multicolumn{2}{|c|}{$\begin{array}{l}\text { Validation cohort }(n= \\
300)\end{array}$} & \multirow[t]{2}{*}{$\begin{array}{l}P \\
\text { value }\end{array}$} \\
\hline & 240 & 26.8 & 80 & 26.7 & \\
\hline $\mathrm{N} 1$ & 656 & 73.2 & 220 & 73.3 & \\
\hline AJCC M Stage(8th ) & & & & & 0.356 \\
\hline MO & 577 & 64.4 & 202 & 67.3 & \\
\hline M1 & 319 & 35.6 & 98 & 32.7 & \\
\hline OS & & & & & 0.897 \\
\hline Alive & 477 & 53.2 & 161 & 53.7 & \\
\hline Dead & 419 & 46.8 & 139 & 46.3 & \\
\hline CSS & & & & & 0.441 \\
\hline Alive & 539 & 60.2 & 188 & 62.7 & \\
\hline Dead due to cancer & 357 & 39.8 & 112 & 37.3 & \\
\hline Survival, months & $38.8 \pm 37.1$ & & $39.2 \pm 33.9$ & & 0.866 \\
\hline
\end{tabular}

\subsection{Univariate and multivariate analyses of prognostic factors in the training cohort}

The predictors of OS and CSS identified from univariate and multivariate analysis of the training cohort are shown in Tables 2 and 3. 
Table 2

Univariate and multivariate analyses of factors associated with OS in the training cohort

Variable

Variable

Age, years

0-55

$56-67$

$\geq 68$

Sex

Female

Male

Tumor size, $\mathrm{mm}$

$<35$

$\geq 35$

Reference

$1.1(0.8,1.3)$

0.663
HR (95\% Cl)
Reference

$1.1(0.9,1.3)$

0.336

Reference

$4.3(3.4,5.4)$

$<$

0.001

Laterality

Right

Left
Multivariate analysis P- $\quad H R(95 \%$ value
Pvalue

Reference

$\begin{array}{llll}1.6(1.2,2.0) & 0.001 & \begin{array}{l}1.2(0.9, \\ 1.6)\end{array} & 0.206 \\ & & l & \\ 2.7(2.1,3.5) & 0.001 & \begin{array}{l}1.7(1.3, \\ 2.2)\end{array} & < \\ & & & 0.001\end{array}$

Reference

$1.3(1.1$,
$1.6)$

0.005

Reference

1.5 (1.2,

0.002

Grade

G1

G2

G3

G4

Pathology

Abbreviations: AJCC, American Joint Committee on Cancer; TNM, tumor-node-metastasis; HR, hazard ratio; $\mathrm{Cl}$, confidence interval. 


\begin{tabular}{|c|c|c|c|c|}
\hline Variable & Univariate analysis & & Multivariat & inalysis \\
\hline $\begin{array}{l}8013 / 3 \text { Large cell neuroendocrine } \\
\text { carcinoma }\end{array}$ & Reference & & Reference & \\
\hline 8041/3 Small cell carcinoma & $1.8(1.2,2.9)$ & 0.006 & $\begin{array}{l}1.5(0.9 \\
2.4)\end{array}$ & 0.091 \\
\hline 8240/3 Carcinoid tumor & $0.1(0.1,0.2)$ & $\begin{array}{l}<.001 \\
0.00\end{array}$ & $\begin{array}{l}0.7(0.5 \\
1.1)\end{array}$ & 0.173 \\
\hline $\begin{array}{l}\text { 8244/3 Mixed adeno-neuroendocrine } \\
\text { carcinoma }\end{array}$ & $0.8(0.5,1.4)$ & 0.472 & $\begin{array}{l}1.5(0.9 \\
2.5)\end{array}$ & 0.158 \\
\hline 8246/3 Neuroendocrine carcinoma & $0.7(0.5,0.9)$ & 0.009 & $\begin{array}{l}1.3(1.0 \\
1.8)\end{array}$ & 0.094 \\
\hline \multicolumn{5}{|l|}{ Operation } \\
\hline No operation & Reference & & Reference & \\
\hline Local tumor excision & $0.0(0.0,0.1)$ & $<.001$ & $\begin{array}{l}0.3(0.1 \\
1.1)\end{array}$ & 0.066 \\
\hline Curative & $0.5(0.4,0.8)$ & 0.005 & $\begin{array}{l}0.7(0.5 \\
1.2)\end{array}$ & 0.181 \\
\hline \multicolumn{5}{|l|}{ Chemotherapy } \\
\hline No & Reference & & Reference & \\
\hline Yes & $3.2(2.6,3.8)$ & $<0.001$ & $\begin{array}{l}0.8(0.6 \\
1.0)\end{array}$ & 0.029 \\
\hline \multicolumn{5}{|l|}{ AJCC TNM Stage (8th ) } \\
\hline 1 & Reference & & & \\
\hline IIA & $2.5(0.9,7.3)$ & 0.095 & & \\
\hline IIB & $2.2(0.9,4.9)$ & 0.068 & & \\
\hline IIIA & $6.0(2.2,16.6)$ & $<.001$ & & \\
\hline IIIB & $4.4(2.3,8.4)$ & $\begin{array}{l}< \\
0.001\end{array}$ & & \\
\hline IV & $15.6(8.3,29.4)$ & $<.001$ & & \\
\hline \multicolumn{5}{|l|}{ AJCC T Stage (8th ) } \\
\hline T1 & Reference & & Reference & \\
\hline
\end{tabular}

Abbreviations: AJCC, American Joint Committee on Cancer; TNM, tumor-node-metastasis; HR, hazard ratio; $\mathrm{Cl}$, confidence interval. 


\begin{tabular}{|c|c|c|c|c|}
\hline \multirow{2}{*}{$\begin{array}{l}\text { Variable } \\
\text { T1a }\end{array}$} & \multicolumn{2}{|c|}{ Univariate analysis } & \multicolumn{2}{|c|}{ Multivariate analysis } \\
\hline & $\begin{array}{l}0.1(0.0,0.2)< \\
0.001\end{array}$ & $<.001$ & $\begin{array}{l}1.7(0.5 \\
5.5)\end{array}$ & 0.387 \\
\hline $\mathrm{T} 1 \mathrm{~b}$ & $\begin{array}{l}0.1(0.0,0.2)< \\
0.001\end{array}$ & $\begin{array}{l}< \\
0.001\end{array}$ & $\begin{array}{l}0.4(0.1 \\
1.8)\end{array}$ & 0.248 \\
\hline T2 & $\begin{array}{l}0.2(0.1,0.4)< \\
0.001\end{array}$ & $<.001$ & $\begin{array}{l}0.7(0.3 \\
2.1)\end{array}$ & 0.575 \\
\hline T3 & $0.3(0.1,0.8)$ & 0.012 & $\begin{array}{l}0.9(0.3 \\
2.3)\end{array}$ & 0.776 \\
\hline $\mathrm{T} 4$ & $0.5(0.2,1.1)$ & 0.093 & $\begin{array}{l}0.9(0.3 \\
2.3)\end{array}$ & 0.827 \\
\hline \multicolumn{5}{|c|}{ AJCC N Stage (8th ) } \\
\hline NO & Reference & & Reference & \\
\hline N1 & $2.5(1.9,3.3)$ & $<.001$ & $\begin{array}{l}1.9(1.4 \\
2.6)\end{array}$ & $<001$ \\
\hline \multicolumn{5}{|c|}{ AJCC M Stage (8th ) } \\
\hline MO & Reference & & Reference & \\
\hline M1 & $4.5(3.7,5.5)$ & $<.001$ & $\begin{array}{l}3.5(2.8 \\
4.4)\end{array}$ & $\begin{array}{l}< \\
0.001\end{array}$ \\
\hline
\end{tabular}


Table 3

Univariate and multivariate analyses of factors associated with CSS in the training cohort

Variable

\section{Variable}

Univariate analysis

$\mathrm{HR}(95 \% \mathrm{Cl})$

Reference

$1.6(1.2,2.1)$

$2.3(1.8,3.0)$

Reference

$1.1(0.9,1.3)$

0.507

0.001

0.001

value

Multivariate analysis

HR (95\% Cl)

$\mathrm{P}-$ value

Age, years

\begin{tabular}{|c|c|c|c|c|}
\hline $0-55$ & Reference & & Reference & \\
\hline $56-67$ & $1.6(1.2,2.1)$ & 0.001 & $1.2(0.9,1.6)$ & 0.26 \\
\hline$\geq 68$ & $2.3(1.8,3.0)$ & 0.001 & $1.4(1.0,1.9)$ & 0.026 \\
\hline \multicolumn{5}{|l|}{ Sex } \\
\hline Female & Reference & & Reference & \\
\hline Male & $1.1(0.9,1.3)$ & 0.507 & $1.3(1.0,1.6)$ & 0.021 \\
\hline \multicolumn{5}{|c|}{ Tumor size, mm } \\
\hline$<35$ & Reference & & Reference & \\
\hline$\geq 35$ & $5.5(4.2,7.1)$ & $<.001$ & $1.6(1.2,2.1)$ & 0.001 \\
\hline \multicolumn{5}{|c|}{ Laterality } \\
\hline Right & Reference & & Reference & \\
\hline Left & $1.1(0.9,1.4)$ & 0.393 & $1.4(1.1,1.8)$ & 0.017 \\
\hline \multicolumn{5}{|l|}{ Grade } \\
\hline G1 & Reference & & Reference & \\
\hline G2 & $3.2(2.0,5.1)$ & $\begin{array}{l}< \\
0.001\end{array}$ & $2.2(1.3,3.5)$ & 0.002 \\
\hline G3 & $14.6(10.0,21.4)$ & $\begin{array}{l}< \\
0.001\end{array}$ & $\begin{array}{l}7.0(4.4 \\
11.0)\end{array}$ & $<.001$ \\
\hline G4 & $17.8(11.8,26.9)$ & $<.001$ & $\begin{array}{l}7.5(4.6 \\
12.2)\end{array}$ & $\begin{array}{l}< \\
0.001\end{array}$ \\
\hline
\end{tabular}

Pathology

8013/3 Large cell neuroendocrine carcinoma

Reference

Reference

8041/3 Small cell carcinoma

$1.8(1.1,2.8)$

0.015

$1.4(0.8,2.2)$

0.201

Abbreviations: AJCC, American Joint Committee on Cancer; TNM, tumor-node-metastasis. 


\begin{tabular}{|c|c|c|c|c|}
\hline \multirow{2}{*}{$\begin{array}{l}\text { Variable } \\
\text { 8240/3 Carcinoid tumor }\end{array}$} & \multicolumn{2}{|c|}{ Univariate analysis } & \multicolumn{2}{|c|}{ Multivariate analysis } \\
\hline & $0.1(0.1,0.2)$ & $<.001$ & $0.6(0.4,1.0)$ & 0.072 \\
\hline $\begin{array}{l}\text { 8244/3 Mixed adeno-neuroendocrine } \\
\text { carcinoma }\end{array}$ & $0.9(0.5,1.4)$ & 0.569 & $1.4(0.8,2.5)$ & 0.18 \\
\hline $8246 / 3$ Neuroendocrine carcinoma & $0.6(0.5,0.9)$ & 0.005 & $1.2(0.9,1.7)$ & 0.213 \\
\hline \multicolumn{5}{|l|}{ Operation } \\
\hline No operation & Reference & & Reference & \\
\hline Local tumor excision & $0.0(0.0,0.1)$ & $<.001$ & $0.6(0.1,7.2)$ & 0.723 \\
\hline Curative & $0.5(0.3,0.8)$ & 0.004 & $0.8(0.5,1.2)$ & 0.263 \\
\hline \multicolumn{5}{|l|}{ Chemotherapy } \\
\hline No & Reference & & Reference & \\
\hline Yes & $3.8(3.1,4.7)$ & $<.001$ & $0.8(0.6,1.0)$ & 0.034 \\
\hline \multicolumn{5}{|l|}{ AJCC TNM Stage (8th ) } \\
\hline I & Reference & & & \\
\hline IIA & $14.8(1.5,142.0)$ & 0.02 & & \\
\hline IIB & $10.2(1.2,84.5)$ & 0.032 & & \\
\hline IIIA & $39.9(4.5,357.1)$ & $<.001$ & & \\
\hline IIIB & $34.9(4.9,249.8)$ & $\begin{array}{l}<.001 \\
0.00\end{array}$ & & \\
\hline IV & $\begin{array}{l}143.2(20.1 \\
1021.2)\end{array}$ & $\begin{array}{l}<.001 \\
0.0\end{array}$ & & \\
\hline \multicolumn{5}{|l|}{ AJCC T Stage (8th ) } \\
\hline T1 & Reference & & Reference & \\
\hline T1a & $\begin{array}{l}0.0(0.0,0.1)< \\
0.001\end{array}$ & $<.001$ & $0.4(0.1,2.6)$ & 0.324 \\
\hline T1b & $\begin{array}{l}0.0(0.0,0.2)< \\
0.001\end{array}$ & $<.001$ & $0.3(0.0,1.5)$ & 0.139 \\
\hline T2 & $\begin{array}{l}0.1(0.1,0.4)< \\
0.001\end{array}$ & $<.001$ & $0.7(0.3,2.0)$ & 0.528 \\
\hline
\end{tabular}

Abbreviations: AJCC, American Joint Committee on Cancer; TNM, tumor-node-metastasis. 


\begin{tabular}{|lllll|}
\hline Variable & Univariate analysis & \multicolumn{2}{l|}{ Multivariate analysis } \\
\hline T3 & $0.3(0.1,0.7)$ & 0.007 & $0.8(0.3,2.0)$ & 0.617 \\
\hline T4 & $0.5(0.2,1.2)$ & 0.111 & $0.9(0.3,2.3)$ & 0.796 \\
AJCC N Stage (8th) & & & & \\
N0 & Reference & & Reference & \\
N1 & $3.4(2.5,4.7)$ & $<$ & $2.2(1.5,3.1)$ & $<$ \\
\hline AJCC M Stage (8th ) & & 0.001 & & \\
\hline M0 & & & & \\
\hline M1 & Reference & & Reference & \\
\hline Abbreviations: AJCC, American Joint Committee on Cancer; TNM, tumor-node-metastasis. & \\
\hline
\end{tabular}

Univariate analysis indicated that age, sex, tumor size, grade, surgery, chemotherapy, AJCC TNM stage (8th), $\mathrm{N}$ stage, and $\mathrm{M}$ stage were significantly associated with the OS rate (Table 2 ). In multivariable survival analysis, age $\geq 68$ years $(P<0.001)$, sex $(P<0.05)$, tumor size $(P<0.05)$, grade $(P<0.001)$, chemotherapy $(P<0.05), \mathrm{N}$ stage $(P<0.001)$, and M stage $(P<0.001)$ were identified as independent prognostic factors associated with the OS rate. Moreover, in CSS analysis, age, sex, tumor size, laterality, grade, chemotherapy, AJCC TNM stage (8th), N stage, and M stage were identified by univariate analysis. However, only age $\geq 68$ years $(P<0.05)$, sex $(P<0.05)$, laterality $(P<0.05)$, tumor size $(P<0.05)$, grade $(P$ $<0.001)$, chemotherapy $(P<0.001), N$ stage $(P<0.001)$, and $M$ stage $(P<0.001)$ were significantly identified in multivariate analysis and further subjected to a CSS nomogram (Table 3, Fig. 1B).

\subsection{Construction and validation of nomograms}

OS and CSS nomograms were constructed based on independent prognostic factors identified by multivariable analysis (Fig. 1). By summing the scores for each selected variable, the probability of a patient's survival can be easily obtained from the nomogram.

We compared the predictive accuracy of our nomograms with the 8th AJCC TNM classification in the training cohort. The $\mathrm{C}$-index of the OS nomogram was 0.8347 (95\% confidence interval [Cl], $0.8171-$ $0.8523)$, which was higher than the C-index of the 8th AJCC TNM staging system $(0.7159 ; 95 \% \mathrm{Cl}$, $0.6762-0.7557)$. The $\mathrm{C}$-index of our CSS nomogram was $0.8668(95 \% \mathrm{Cl}, 0.0 .8506-0.883)$, which was also superior to the 8 th AJCC TNM staging system $(0.7366 ; 95 \% \mathrm{Cl}, 0.6955-0.7776)$. These results demonstrated that our nomograms had superior survival predictive ability compared with the AJCC TNM staging system. To confirm the predictive power of the nomograms, further applications were made in the validation cohort, yielding the C-index of $0.8345(95 \% \mathrm{Cl}, 0.8044-0.8646)$ and $0.8209(95 \% \mathrm{Cl}, 0.7808-$ 0.861) for the OS nomogram and CSS nomogram, respectively. The calibration curve revealed the 
agreement between the predicted and actual survival (Fig. 2). In addition, the area under the ROC curve (AUC) was high for both the training and validation cohorts (Fig. 3).

\section{Discussion}

With widespread use of gastrointestinal endoscopy for cancer screening and increased public health awareness [1], the incidence of neuroendocrine tumors has been increasing in recent years. The SEER study in the United States showed an age-adjusted incidence rate of gastroenteropancreatic neuroendocrine tumors of 3.56 per 100,000 inhabitants (2000-2012) [1]. It is well known that the primary site of NENs is an important prognostic factor for survival [2]. However, most previous studies have analyzed rectal NENs and colon NENs as if they were originating from the same primary site. Nevertheless, it has become clear that colon NENs are a different disease from rectal NENs. Rectal NENs are commonly (but not exclusively) small and generally of low to intermediate grade (grades 1 [G1] or 2 [G2]), whereas colon NENs are often aggressive, poorly differentiated, and of higher grade (G3) [17]. Additionally, the OS rate of patients with colon NENs is significantly lower than that of patients with rectal NENs [18]. Therefore, it is necessary to perform separate statistical analysis for colon NENs.

In the present study, we developed and validated new nomogram models for predicting the OS and CSS in patients with colon NENs using the SEER data. The nomogram incorporated independent prognostic factors associated with OS and CSS that were identified in the multivariable analysis, including age, sex, tumor size, grade, chemotherapy, $\mathrm{N}$ stage, and M stage. The OS and CSS nomograms exhibited high discriminatory accuracy in the training cohort with C-indexes of 0.8347 and 0.8668 , respectively, which was also confirmed in the validation cohort with C-indexes of 0.8345 and 0.8209 , respectively. Additionally, the calibration curves exhibited excellent agreement between predicted and observed OS and CSS in both cohorts, indicating that the nomograms have good performance for estimating the prognosis of colon NENs.

Colon NENs are extremely rare, constituting only $1 \%$ of all colon neoplasms and $<11 \%$ of gastrointestinal NENs [19]. There are few studies related to colon NENs. According to Smith et al. [21], high-grade colorectal NECs are very aggressive tumors with poor prognosis. Patients have a slightly better prognosis if they do not have metastatic disease, if they have an adenocarcinoma component within the tumor, or if they respond to chemotherapy [21]. Surgery, especially in the presence of metastatic disease, may not provide any survival benefit for most patients [21]. Fields et al. [22] demonstrated that the total number of positive lymph nodes was an independent predictor of survival in patients with colon NENs. Namely, the prognosis differed between patients with no positive lymph nodes, one positive lymph node, two to nine positive lymph nodes, and 10 or more positive lymph nodes [22].

We collected only 35 cases of colon NENs in Jiangsu province, China in a 10-year period. Since colon NENs are relatively rare, it is difficult to perform this nomogram study with cases based on single or even multiple institutions. Therefore, to develop a nomogram that may be widely applied to all patients with colon NENs, we used the SEER public database, which includes the largest sample size of colon NENs to 
date. Multivariate analysis showed that the $\mathrm{N}$ and $\mathrm{M}$ stages were significantly associated with OS and CSS. Meanwhile, grade was also a strong independent prognostic factor. Both univariate and multivariate analyses indicated that age $\geq 68$ years and tumor size $\geq 35 \mathrm{~mm}$ significantly contribute to poor survival.

The most commonly used predictive system for colon NENs is the AJCC TNM classification, which includes three clinical parameters: tumor size $(T)$, lymph node status $(N)$, and distant metastasis $(M)$. In contrast, in the present study, we constructed a new nomogram that incorporates more prognostic factors to accurately predict outcomes in patients with colon NENs. The nomogram models exhibited high discrimination accuracy in the training cohort (C-index 0.8347 for OS and 0.8668 for CSS) and demonstrated better survival predictive ability than the 8th AJCC TNM staging system (C-index 0.7159 for OS and 0.7366 for CSS). These results were confirmed in the validation cohort as well. Moreover, the calibration curves showed the agreement between the predicted and actual survival, indicating excellent performance of the nomograms in predicting the prognosis of colon NENs.

Clinicians can use the total score provided by the nomograms constructed in this study to individualize treatment for patients with colon NENs. The nomograms can distinguish subgroups of patients at different levels of risk, thereby avoiding overtreatment in lower-risk patients and pursuing more aggressive treatment and close follow-up in higher-risk patients. In addition, the nomograms can be used as a prognostic device to assess the prognosis of patients with colon NENs more accurately.

The present study still had some limitations. First, neuroendocrine biomarkers, such as chromogranin A (CgA), synaptophysin (Syn), and CD56, were not available in the SEER database. Therefore, it was impossible to evaluate these parameters and integrate them into the nomogram. Moreover, in the SEER database, Ki-67 index was classified as well differentiated, moderately differentiated, and poorly differentiated/undifferentiated, which is why it was categorized as a categorical variable in the nomogram; however, $\mathrm{Ki}-67$ is a continuous variable in clinical practice. Therefore, the use of a continuous $\mathrm{Ki}-67$ index variable may be more useful in developing nomograms and predicting outcomes more accurately. Second, the SEER database did not contain detailed data regarding chemotherapy regimens, which restricted us from further evaluating the impact of different drug treatments on the survival of colon NENs. Third, for the validation of nomograms, both internal and external validation cohorts are recommended. Due to the rarity of colon NENs, only 35 cases were collected in Jiangsu province, China from 2010 to 2019, and that is why only internal validation could be performed in this study. Despite these inherent limitations, our prognostic model still provides a helpful tool for clinicians to ensure better decision making and prognosis estimation.

\section{Conclusion}

In conclusion, we identified seven independent prognostic factors of survival, including age, sex, tumor size, grade, chemotherapy, $\mathrm{N}$ stage, and $\mathrm{M}$ stage, and developed new nomograms to predict OS and CSS in patients with colon NENs using the SEER data. Our nomograms demonstrated a better survival 
predictive ability than the 8th AJCC TNM staging system, and thus can be valuable tools for individualized clinical decisions.

\section{List Of Abbreviations}

NENs: neuroendocrine neoplasms; NET: neuroendocrine tumor; NEC:neuroendocrine carcinoma; MiNEN: mixed neuroendocrine non-neuroendocrine neoplasm; MANEC: mixed adeno-neuroendocrine carcinoma; OS: overall survival; CSS: cancer-specific survival; AJCC: American Joint Committee on Cancer; TNM: tumor-node-metastasis; SEER: Surveillance, Epidemiology, and End Results; WHO: World Health Organization; ICD-0-3: International Classification of Diseases for Oncology, Third Edition; Cl: confidence interval; C-index: Concordance index; ROC:receiver operating characteristic; AUC: area under the timedependent ROC curve.

\section{Declarations}

Ethics approval and consent to participate

Not applicable.

\section{Consent for publication}

Not applicable.

\section{Availability of data and materials}

The datasets supporting the conclusions of this article are available in the SEER database at https://seer.cancer.gov/seerstat/.

\section{Competing interests}

The authors declare that they have no conflict of interest.

\section{Funding}

The study was supported by the Medical Key Talents Project of Jiangsu Province (Grant No. ZDRCA2016008) and the 333 Project of Jiangsu Province (Grant No. BRA2017535).

\section{Authors' contributions}

Contributions: (I) Conception and design: All authors; (II) Administrative support: Qiyun Tang; (III) Provision of study materials or patients: All authors; (IV) Collection and assembly of data: Ruitong Xu; (V) Data analysis and interpretation: All authors; (VI) Manuscript writing: All authors; (VII) Final approval of manuscript: All authors. 


\section{Acknowledgment}

We thank LetPub (www.letpub.com) for its linguistic assistance and scientific consultation during the preparation of this manuscript.

\section{References}

1. Shen $C$, Yin Y, Chen H, Tang S, Yin X, Zhou Z, et al. Neuroendocrine tumors of colon and rectum: validation of clinical and prognostic values of the World Health Organization 2010 grading classifications and European Neuroendocrine Tumor Society staging systems. Oncotarget. 2017;8(13):22123-34.

2. Dasari A, Shen $C$, Halperin $D$, Zhao B, Zhou $S, X u Y_{\text {, }}$ et al. Trends in the incidence, prevalence, and survival outcomes in patients with neuroendocrine tumors in the united states. JAMA Oncol. 2017;3(10):1335-42.

3. Yao JC, Hassan M, Phan A, Dagohoy C, Leary C, Mares JE, et al. One hundred years after "carcinoid": epidemiology of and prognostic factors for neuroendocrine tumors in 35,825 cases in the United States. J Clin Oncol. 2008;26(18):3063-72.

4. Fang $C$, Wang W, Zhang $Y$, Feng $X$, Sun J, Zeng $Y$, et al. Clinicopathologic characteristics and prognosis of gastroenteropancreatic neuroendocrine neoplasms: a multicenter study in South China. Chin J Cancer. 2017;36(1):51.

5. Wang YH, Lin Y, Xue L, Wang JH, Chen MH, Chen J. Relationship between clinical characteristics and survival of gastroenteropancreatic neuroendocrine neoplasms: A single-institution analysis (19952012) in South China. BMC Endocr Disord. 2012;12:30.

6. Fan JH, Zhang YQ, Shi SS, Chen YJ, Yuan XH, Jiang LM, et al. A nation-wide retrospective epidemiological study of gastroenteropancreatic neuroendocrine neoplasms in china. Oncotarget. 2017;8(42):71699-708.

7. Lin HH, Lin JK, Jiang JK, Lin CC, Lan YT, Yang SH, et al. Clinicopathological analysis of colorectal carcinoid tumors and patient outcomes. World J Surg Oncol. 2014;12:366.

8. Broecker JS, Ethun CG, Postlewait LM, Le N, McInnis M, Russell MC, et al. Colon and rectal neuroendocrine tumors: are they really one disease? a single-institution experience over 15 years. Am Surg. 2018;84(5):717-26.

9. Amin MB, Creene FL, Edge SB, et al. AJCC Cancer Staging Manual. 8th ed. New York: Springer; 2016.

10. Ricardo V, Lloyd, Robert Y, Osamura G, Klöppel JR. 2017 WHO Classification of Tumours of Endocrine Organs(4th edition). Lyon: international agency for research on cancer(IARC).

11. Greene FL, Sobin LH. The staging of cancer: a retrospective and prospective appraisal. CA Cancer J Clin. 2008;58(3):180-90.

12. Karakiewicz PI, Briganti A, Chun FK, Trinh QD, Perrotte P, Ficarra V, et al. Multi-institutional validation of a new renal cancer-specific survival nomogram. J Clin Oncol. 2007;25(11):1316-22. 
13. Wierda WG, O'Brien S, Wang X, Faderl S, Ferrajoli A, Do KA, et al. Prognostic nomogram and index for overall survival in previously untreated patients with chronic lymphocytic leukemia. Blood. 2007;109(11):4679-85.

14. Mariani L, Miceli R, Kattan MW, Brennan MF, Colecchia M, Fiore M, et al. Validation and adaptation of a nomogram for predicting the survival of patients with extremity soft tissue sarcoma using a threegrade system. Cancer. 2005;103(2):402-8.

15. Wang L, Hricak H, Kattan MW, Chen HN, Scardino PT, Kuroiwa K. Prediction of organ-confined prostate cancer: incremental value of MR imaging and MR spectroscopic imaging to staging nomograms. Radiology. 2006;238(2):597-603.

16. National cancer institution. Surveillance, Epidemiology, and End Results (SEER) Research Database (1975-2016). https://seer.cancer.gov. Accessed April 1, 2019.

17. Ramage JK, De Herder WW, Delle Fave G, Ferolla P, Ferone D, Ito T, Ruszniewski P, et al. ENETS Consensus Guidelines Update for Colorectal Neuroendocrine Neoplasms. Neuroendocrinology. 2016;103(2):139-43.

18. Man D, Wu J, Shen Z, Zhu X. Prognosis of patients with neuroendocrine tumor: a SEER database analysis. Cancer Manag Res. 2018;10:5629-38.

19. Maggard MA, O'Connell JB, Ko CY. Updated population-based review of carcinoid tumors. Ann Surg. 2004;240(1):117-22.

20. Huitzil-Melendez FD, Capanu M, O'Reilly EM, et al. Advanced hepatocellular carcinoma: which staging systems best predict prognosis? J Clin Oncol. 2010;28(17):2889-95.

21. Smith JD, Reidy DL, Goodman KA, Shia J, Nash GM. A retrospective review of 126 high-grade neuroendocrine carcinomas of the colon and rectum. Ann Surg Oncol. 2014;21(9):2956-62.

22. Fields AC, McCarty JC, Lu P, Vierra BM, Pak LM, Irani J, et al. Colon Neuroendocrine Tumors: A New Lymph Node Staging Classification. Ann Surg Oncol. 2019;26(7):2028-36.

\section{Figures}



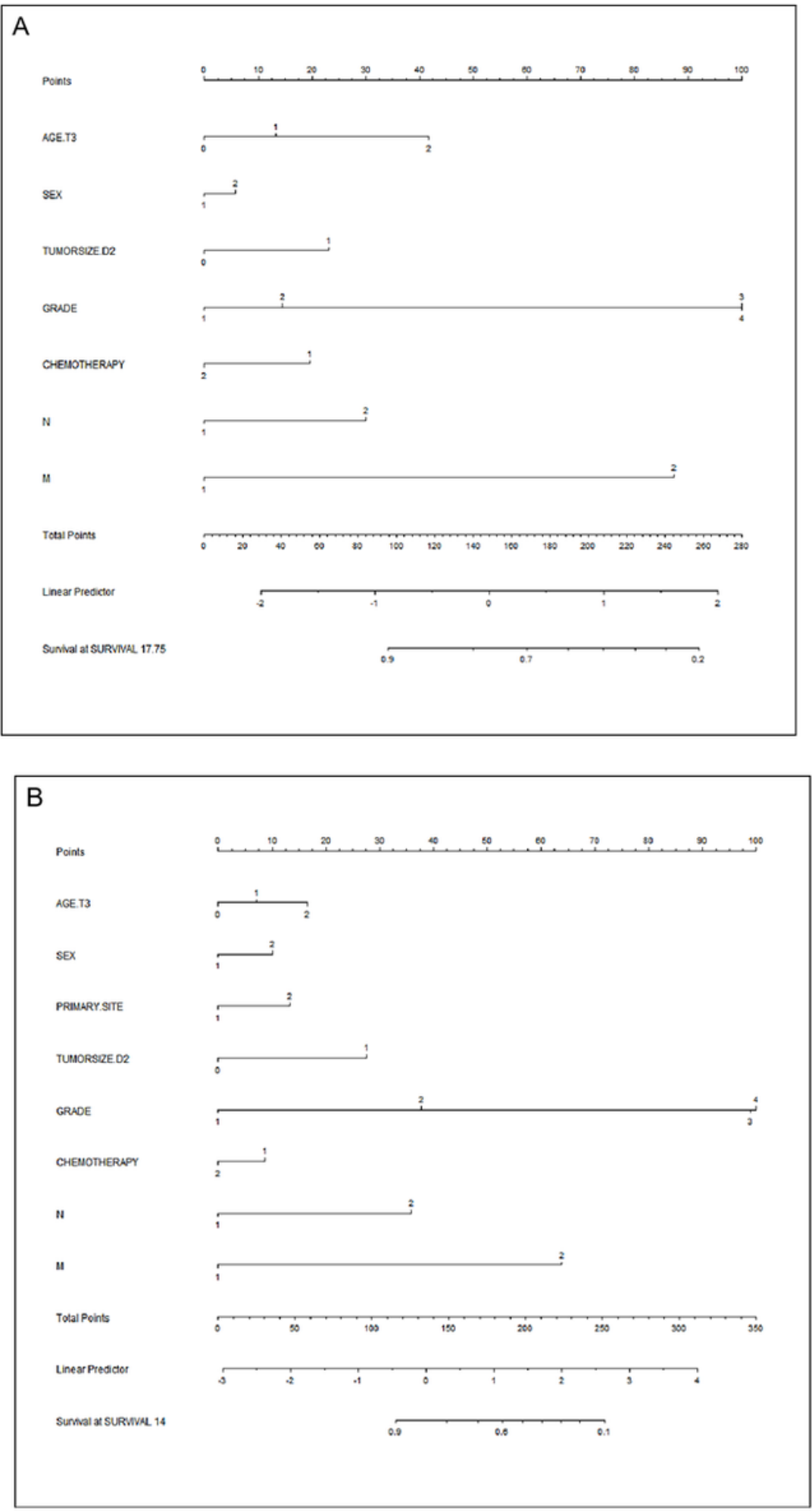

\section{Figure 1}

OS and CSS associated nomograms for colon NENs patients. (A) OS nomogram for colon NENs patients; (B) CSS nomogram for colon NENs patients. 

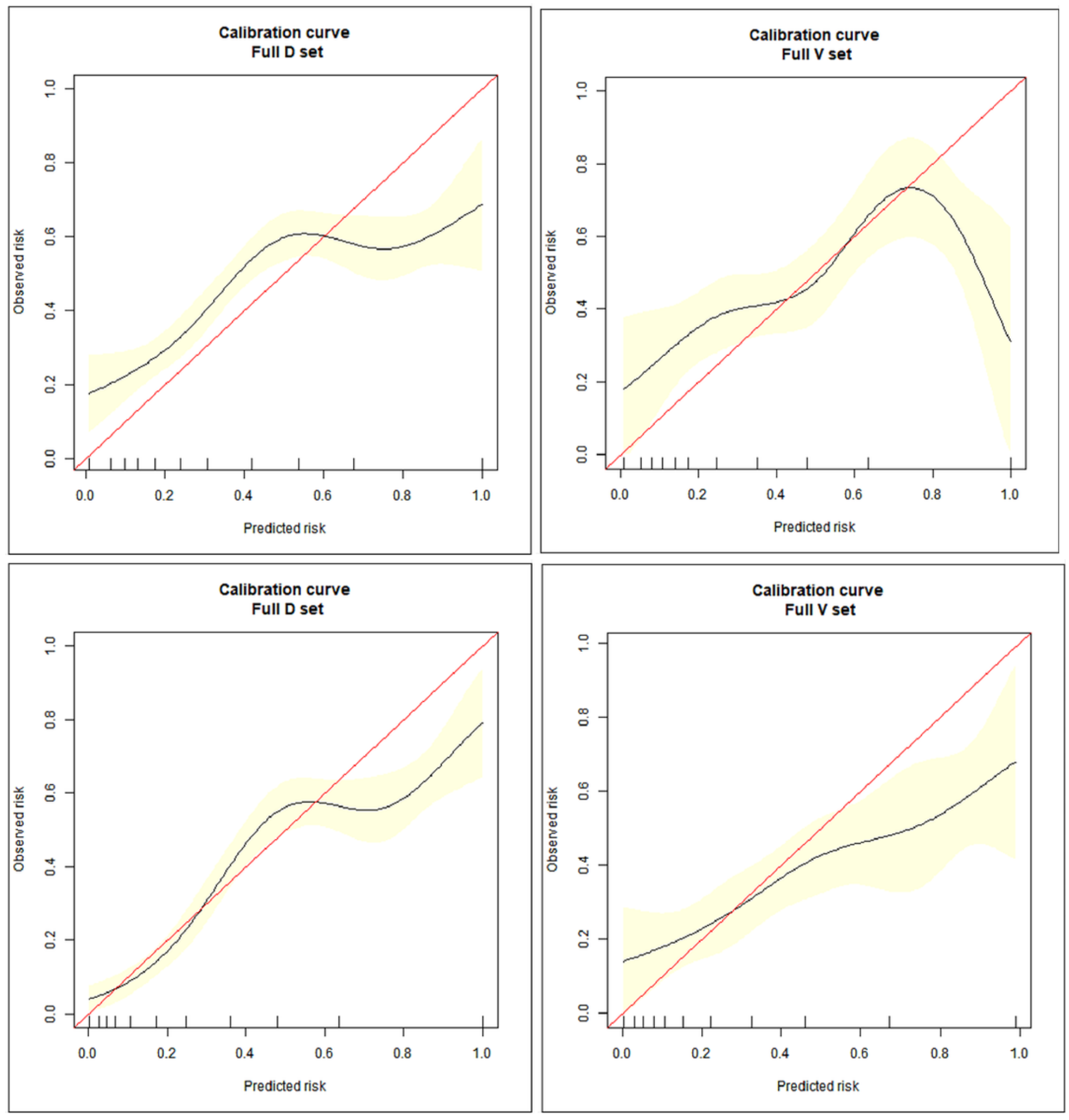

\section{Figure 2}

Calibration curves of the OS nomogram in the (a) training cohort and (b) validation cohort. Calibration curves of the CSS nomogram in the (c) training cohort and (d) validation cohort. The $x$ axis represents the nomogram predicted survival rate, whereas the $y$ axis represents the actual survival rate. 

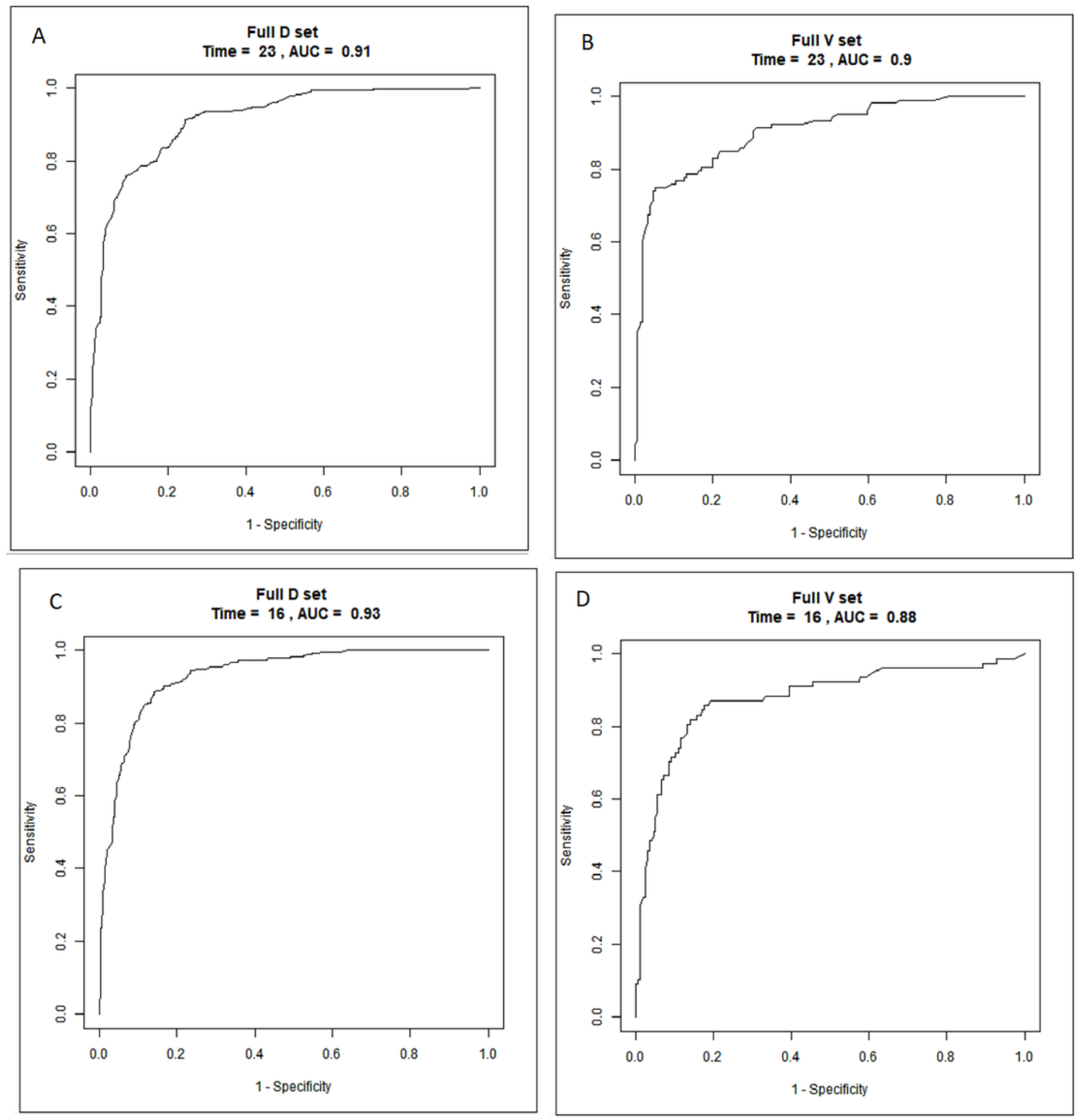

Figure 3

The AUCs of the OS nomogram in the (a) training cohort and (c) validation cohort. AUCs of the CSS nomogram in the (b) training cohort and (d) validation cohort. 